\title{
Defining an "ideal" heritage speaker: Theoretical and methodological challenges I Reply to peer commentaries
}

\section{Citation}

Benmamoun, Elabbas, Silvina Montrul, and Maria Polinsky. “Defining an 'ideal' Heritage Speaker: Theoretical and Methodological Challenges I Reply to Peer Commentaries." Theoretical Linguistics 39 (3-4). doi:10.1515/tl-2013-0018. http://dx.doi.org/10.1515/tl-2013-0018.

\section{Published Version}

doi:10.1515/tl-2013-0018;doi:10.1515/tl-2013-0018

\section{Permanent link}

http://nrs.harvard.edu/urn-3:HUL.InstRepos:11856180

\section{Terms of Use}

This article was downloaded from Harvard University's DASH repository, and is made available under the terms and conditions applicable to Open Access Policy Articles, as set forth at http:// nrs.harvard.edu/urn-3:HUL.InstRepos:dash.current.terms-of-use\#OAP

\section{Share Your Story}

The Harvard community has made this article openly available.

Please share how this access benefits you. Submit a story.

\section{Accessibility}


DEFINING AN “IDEAL” HERITAGE SPEAKER: THEORETICAL AND METHODOLOGICAL

CHALLENGES

REPLY TO PEER COMMENTARIES

Elabbas Benmamoun, Silvina Montrul and Maria Polinsky

"Linguistic theory is concerned primarily with an ideal speaker-listener, in a completely homogeneous speechcommunity, who knows its (the speech community's) language perfectly and is unaffected by such grammatically irrelevant conditions as memory limitations, distractions, shifts of attention and interest, and errors (random or characteristic) in applying his knowledge of this language in actual performance.” (Chomsky 1965: 3)

We would like to thank all our colleagues who commented on our article. They have all engaged insightfully with the ideas we laid out and have provided thoughtprovoking, valuable, and fair criticism. We are grateful for the opportunity to respond to the commentaries by clarifying and elaborating on some of the ideas we presented, with the following broad themes: defining heritage speakers, finding theoretical relevance in heritage languages, contributing to the theory of language acquisition, and sharpening the methodology of research. 


\section{$1 \quad$ Who is a heritage speaker?}

\subsection{Addressing the variance in the heritage population}

As Kupisch, Meisel, Soltan, and Dąbrowska point out, the heterogeneity of the heritage-speaking population makes characterizing heritage speakers a challenging task. Indeed, the problem of defining and identifying heritage speakers is well-known in the literature (Beaudrie and Fairclough 2012, de Bot and Gorter 2005, Carreira 2004, Carreira and Kagan 2011, Fishman 2001, He 2010, Hornberger and Wang 2008, King and Ennser-Kananen 2013, Polinsky and Kagan 2007, Van Deusen-Scholl 2003); to date, all of the definitions advanced have been appropriate for the specific context and communities they describe, yet hard to apply beyond that. As Carreira (2004) puts it, we do not have a "size that fits all" when it comes to defining or characterizing heritage speakers - this is why most articles about heritage speakers spend a significant portion of their introductory sections discussing issues concerning the label 'heritage speaker' and connotations of that term.

Disclaimers aside, we agree that clear definitions are critical for delimiting the object of study in any field, for applying methodologies to an object of study, and for contributing to theoretical models. The field of heritage languages is not different in this respect. Throughout our keynote article, we employed a rather informal definition that built on the one proposed by Valdés (2000). ${ }^{1}$ Roughly, we define heritage speakers as asymmetrical bilinguals who learned language $\mathrm{X}$ - the 'heritage language' - as an L1 in

\footnotetext{
${ }^{1}$ Heritage speakers are "individuals raised in homes where a language other than English is spoken and who are to some degree bilingual in English and the heritage language," according to Valdés $(2000,2005)$.
} 
childhood, but who, as adults, are dominant in a different language. Adopting this or any other definition requires addressing the distinction between heritage speakers in a broad sense and heritage speakers in a narrow sense. Defined broadly, as per Fishman (1981, 2006), a heritage speaker is anyone who has an ethnic, cultural, or other connection with a language, regardless of whether that person learned the heritage language as a child. ${ }^{2}$ Defined narrowly, a person is a heritage speaker if and only if he or she grew up learning the heritage language and has some proficiency in it. It is the latter group that we focus on in our work. ${ }^{3}$

The broad and narrow notions of heritage language intersect in an important area: that of minority language. This is a topic we wish to address clearly and immediately. As Kupisch correctly notes, in our paper, we characterize heritage speakers as early bilingual individuals whose native language (or one of their native languages) is a minority language. While this is true, it seems that we inadvertently conflated the terms 'minority language' and 'immigrant language' in our discussion, thereby implying that only immigrant languages can be heritage languages. This is emphatically not the case. In our paper, we focused on heritage speakers who come from minority communities in the United States; due to the long history of English sociopolitical dominance in the U.S., the heritage languages we investigated were necessarily all immigrant languages. However, it was not our intention to suggest that only immigrant languages can be

\footnotetext{
${ }^{2}$ This is the case, for example, for members of Muslim communities of non-Arab background in North America, who may feel some cultural and religious affinity with Arabic, and may even acquire the classical/formal variety of the language in school or the mosque, but were never exposed to the spoken language as L1 within their family and community contexts.

${ }^{3}$ See Polinsky and Kagan (2007) for the difference between the broad and narrow definitions of heritage speakers.
} 
heritage languages. In fact, given the narrow definition of 'heritage speaker' we are embracing, the immigrant language profile is only one possible type of heritage language pattern; any language can be a heritage language and any speaker can be a heritage speaker, given the right context. ${ }^{4}$

Indeed, Fishman $(2001,2006)$ refers to immigrant languages, colonial languages (e.g., Dutch and German in North America), and indigenous languages all over the world as heritage languages, and we agree with this overall characterization. We also agree with Meisel and Kupisch that speakers of languages like Irish in Ireland, Welsh in Wales, Basque in Spain, Finnish in Sweden, Quechua in Perú, Dyirbal in Australia, Inuttitut in Canada - that is, indigenous languages which may or may not have coofficial status in their territories - are also heritage language speakers, and most of their younger speakers are heritage speakers. Although we did not include speakers from these profiles in our review, there are several studies that discuss the same linguistic issues we discussed in our article in these contexts: see for example Sherkina-Lieber (2011) and Sherkina-Lieber et al. (2011) for Inuttitut, Schmidt (1985) for Dyirbal, and Hindley (1990) for Irish ${ }^{5}$. Our discussion was and is primarily concerned with the psycholinguistic characterization of heritage speakers themselves, rather than the sociolinguistic status of the heritage language.

\footnotetext{
${ }^{4}$ See Montrul (2008) for an enumeration of different psycholinguistic learner profiles and types of bilinguals.

${ }^{5}$ However, not all minority languages display the properties of heritage languages in the diaspora. The strength of a minority language depends on the extent of its contact with the dominant language, urbanization and demographic dislocation, literacy and education, and the prevailing political and socio-economic conditions.
} 
Another important point to be made here is that the term 'minority language' must necessarily be applied locally, rather than globally, to the notion of heritage languages. In other words, any language can be a (local) minority language, regardless of its worldwide status, as long as it is not the dominant language of the country under discussion. English is no exception. ${ }^{6}$ Viswanath's (2013) study provides an example of English in a minority/heritage context. Viswanath found that English-speaking immigrants in Israel show non-target linguistic performance in several areas of morphosyntax. Yip and Mathews (2007) investigated heritage English in Hong Kong in their study of the simultaneous acquisition of English and Cantonese by their three children. Finally, there are several case studies (Reetz-Kurashige 1999, Tomiyama 1999, Tomiyama 2008, Yoshitomi 1999) which examine second language attrition of English, or what we would call 'heritage language reversal', in the context of Japanese returnees: subjects who were either born in an English-speaking country or immigrated very young, and lived for more than two years abroad before returning to Japan for the remainder of their childhood. $^{7}$ While abroad, these students attended public elementary schools with full instruction in English; during this period, English became their dominant language and Japanese their weaker language. The studies follow the linguistic development of these children after their return to Japan and document the different degrees of English language forgetting experienced by the subjects after their reinsertion into a Japanese environment. Once these children returned to their home country, input and use of English (the original dominant language) decreased significantly. Within two years of

${ }^{6}$ Fishman (2006) also emphasizes minority status as a crucial part of the definition of a heritage language, but seems to imply that it would be hard to consider English a heritage language because it enjoys high prestige all over the world. We disagree.

${ }^{7}$ See also Flores (2010) for an example of this type of population in a European context. 
arrival, the children started to forget words and lose grammatical abilities. Although the learning context of these children is different, they are nevertheless heritage speakers of English in the narrow sense, because spoken English was part of their cultural and linguistic upbringing while living abroad.

Kupisch and Meisel also point out that our definition of heritage speakers says little about the composition of the speaker's family. Heritage speakers who belong to an immigrant community are likely to have two parents who are themselves native speakers of the heritage language, or one heritage language-speaking parent and one majority language-speaking parent. Kupisch and Meisel mention several studies emerging from Europe and Canada which suggest that simultaneous bilingual children growing up in a one-parent/one-language household develop high(er) levels of proficiency in their two languages. We do not deny or disqualify these findings, but we want to emphasize that context of acquisition does not have a consistent effect across the board in heritage language studies. Consider, for instance, a study by Sánchez-Walker (2013) on the comprehension of subject and object relative clauses in Spanish. Although relative clauses in Spanish and English are formed similarly, Spanish shows two types of word order inside the relative clause: one that matches English, and another that doesn't. Among the heritage speakers tested by Sánchez-Walker, 60\% had two Spanish-speaking parents, whereas the other $40 \%$ had one Spanish-speaking parent and one Englishspeaking parent. Sánchez-Walker found that the heritage speakers with two Spanishspeaking parents showed native-like comprehension of Spanish relative clauses with both word orders, whereas those who had only one Spanish-speaking parent performed at ceiling with the English-like relative clauses, but were very inaccurate with the non- 
English word order. This study and others like it indicate that quantity of input, as estimated by the sum of the parents' native languages, can also play a role in the resulting grammatical competence of heritage speakers. We will return to this issue in section 3 .

\subsection{Heritage speakers as child bilinguals}

Kupisch and Meisel remind us that, since the 1980s, a vast and important body of research has been conducted on child bilingualism and bilingual first language acquisition in Europe (De Houwer 2009, Deuchar and Quay 2000, Döpke 1992, Ezeizabarrena Segurola 2001, Lanza 2004, Meisel 1994, 2001, 2007, Müller and Hulk 2001), and, we would like to add, in Canada (Genesee 1989, Genesee et al. 1995). This work has shown that young children keep their two linguistic systems separate from the onset of bilingual acquisition and go through the same developmental milestones in each language that monolingual children do. Due to scope limitations, in our paper, we did not relate our account of adult heritage speakers to this work on child bilinguals. By this omission, we did not mean to imply that successful cases of bilingualism such as those reported in Europe are not part of the heritage speaker research agenda. These cases of bilingualism, which largely occur in professional families rather than immigrant communities, are usually referred to under the label 'bilingual acquisition' in Europe; nevertheless, as long as the languages of these bilingual children are in a majorityminority relationship in the country of study and the focus of study is the minority language, then these children constitute heritage speakers, according to our definition.

Serratrice $(2001,2002)$ investigates this situation in her study of Carlo. Carlo was the son of an American father and an Italian mother living in Scotland, UK. Both parents were academics. For the first five months of his life, Carlo's father addressed him in 
English (the majority language in Scotland), and his mother in Italian. When Carlo was five months old, he started to attend an English-speaking day care for half a day, every day of the week. At home, he spoke Italian with his mother and the older sibling. On weekends, he was cared for by an Italian-speaking nanny. Even though Carlo is reported to be bilingual in Italian and English as an adult, Italian remains a heritage language in this case because it is not the language of the wider speech community in the UK. Similarly, Von Raffler-Engel (1965) describes an Italian boy who grew up in Florence, Italy. His mother always addressed him in Italian and his father, who was American, addressed him in English. The parents spoke English to each other at home, and it was clear that the boy understood the language. Even so, he refused to speak English, because his broader environment was Italian-speaking. When children realize that their home language is a minority language and is not spoken beyond the home, they switch to the majority language spoken by their social group. Caldas and Caron-Caldas (2000), a French-English family who spent part of each year in the United States (Louisiana) and part in French Canada, describe a similar situation, where the language of socialization at school determined the degree of minority language use by their three French-English bilingual children in Canada and the United States. People often assume that children growing up exposed to two languages will ultimately know both languages very well, and many of the Canadian and European studies mentioned earlier seem to support this assumption. This is not always the case, however, especially in the United States.

Although we emphasized in our article that the vast majority of heritage speakers do not show full acquisition of the heritage language, we agree with Kupisch that ultimate attainment of the heritage language is not relevant to the definition of an 
individual as a heritage speaker. It is the context of a speaker's acquisition of a language, rather than the extent to which he has mastered that language, that defines him as a heritage speaker. Valdés' $(2000,2005)$ definition of heritage speakers stresses the fact that heritage speakers are all bilingual to some extent, although the range of proficiency in the heritage language varies widely, from mere receptive ability to full fluency. We agree with this assessment, and believe that it pertains to both simultaneous and sequential bilinguals, as discussed in Montrul (2008). The bilingual speakers investigated in the European studies mentioned by Kupisch and Meisel therefore fit the definition of heritage speakers we adopt: they are simply high proficiency heritage speakers. The reality is, however, that as far as research in the United States and Canada is concerned, there are very few, if any, empirical studies of adult heritage speakers who have full command of their heritage language. We hope that the issues we raise in our article encourage other researchers to conduct these studies.

Kupisch notes that bilingual speakers in Europe tend to end up with stronger grammatical command of their two languages, including the minority language, compared to their counterparts in the United States. She cites two recent studies on adult bilinguals in Europe to illustrate this point: a study on the use of French gender by German speakers, and a study on the definiteness effect in Turkish speakers. Although there has yet to be a U.S. study of high-proficiency heritage speakers (see Carreira and Kagan 2011), this does not necessarily imply that such speakers do not exist, or that they are measurably less proficient than their bilingual European counterparts. If it does turn out that high-proficiency heritage speakers are more common in Europe than in the United States, the reasons for these differences are likely to be found in general attitudes 
towards bilingualism and multilingualism, language policies, and language practices and ideologies within the immigrant communities in Europe and the United States, as well as socioeconomic status and level of education of heritage language speakers in the two locations. This point is emphasized by Dąbrowska as well. To properly investigate this question, studies will need to be undertaken which test the same population in Europe and in the United States. For instance, a study examining the acquisition and maintenance of Italian in Germany as opposed to the acquisition and maintenance of Italian in the United States would allow us to directly compare the effects of social factors in these two environments.

Heritage speakers are not always highly proficient across the board in Europe. Sociolinguists who work with ethnic minority languages in Europe report patterns of intergenerational language loss, incomplete acquisition, and attrition similar to those we report in our paper. These findings run counter to the findings of studies on early bilingualism in middle-class and professional families who are not part of ethnic communities in Europe. Here are some examples:

"With respect to the acquisition of ethnic community languages it is clear that the submersion in a second language environment may result in stagnation (Verhoeven 1991a,b; Verhoeven and Boeschoten 1986; De Ruiter 1991; Pfaff 1991). Due to restricted first language input, ethnic minority children may have a lower level of mother-tongue competence. There is clear evidence that second generation Turkish and Moroccan children born in the Netherlands do not reach native-like proficiency levels, due to reduced input conditions." (Extra and Verhoeven 1993: 95)

"Although their daily exposure to both languages initially led us to expect that the children would display the characteristics of "simultaneous acquisition of two first languages", our analysis of their developing competence to date reveals that their language acquisition patterns differ significantly from those "Type 1" bilingual children of mixed marriages most frequently reported in the literature on early child bilingualism. Instead, we find a pattern of successive first and second language acquisition with clear patterns of language dominance. The majority of 
Turkish children are Turkish dominant. But some children are German dominant: the acquisition for Turkish morphosyntax is like those of monolinguals only in some respects, while some structures do not develop to the same extent, if at all, a pattern termed "stagnation" by Verhoeven and Boeschoten (1986). The few German children in the KITA project do not develop productive competence in Turkish, despite constant input from Turkish caretakers and Turkish-speaking children. Turkish-dominant children are indistinguishable from Turkish monolinguals (virtually no case errors), but have deficiencies in German (they make case errors). The German-dominant Turkish speakers produce case errors in Turkish and also produce case errors in German." (Pfaff 1993: 125-126)

"Up until the age of five, the L1 of Turkish children in the Netherlands seems to be at the same level of development when compared to their monolingual peers in Turkey. However, from the age of five onwards, when they have entered primary school, their L1 development curve levels off much stronger than their peers in Turkey. This suggests that certain linguistic devices occurring in later stages of language development may never be acquired in this specific situation." (Schaufeli 1993: 147)

Commenting on Serbian and Croatian second generation immigrants in the Netherlands, Pavlinić (1993: 114) writes,

"the compositions of 10-18 year old students show that their native language varieties are substantially influenced by the second language submersion context. Both intra- and interlingual characteristics of language change could be evidenced at all levels of linguistic system. It was found that restricted input leads to a reduced language variety. Most reductions were counted at the level of syntax."

How do we reconcile the vast body of psycholinguistic work mentioned by Kupisch and Meisel with these observations emerging from the sociolinguistic literature on European minority languages? It seems to us that psycholinguists studying bilingualism and sociolinguists studying language acquisition and change in ethnic minority communities often look at different populations. The two research communities need to come together to understand the reasons behind their divergent findings. At the same time, more transnational studies of the same heritage language in different contexts—-say, Koreans in the United States, China and Argentina, or Moroccans in Spain and France-will tell us 
more about how the sociolinguistic and sociopolitical environment in the host country contributes to language maintenance and loss in these populations. ${ }^{8}$

\section{$2 \quad$ Is linguistic theory ready for heritage languages?}

\section{$2.1 \quad$ No longer focusing on monolingual speakers}

One of the main goals of our paper is to show that heritage speakers provide new, valuable data for testing and advancing current theories. Our goal has been to introduce a more complex conception of 'native speaker' than the one traditionally assumed. The response we have received on this point suggests that the time for such a conceptual shift has arrived. As Lohndal points out in his commentary, linguistic theory has achieved a great deal of sophistication by exploring language from the perspective of an idealized monolingual speaker; as a result, we are now in a good position to expand this theory to "messier" environments where two or more languages meet. ${ }^{9}$ This does not mean that the critical distinction between I-language and E-language should be abandoned-on the contrary, the new goal of our work is to understand what the competence of heritage speakers is. This raises two questions (echoed by Lohndal, Meisel, and Muysken):

\footnotetext{
${ }^{8}$ A comparative study of the distribution of immigrant populations in Europe and the United States is also necessary. It may turn out that Arabic heritage speakers in Dearborn, Michigan pattern with Arabic heritage speakers in Marseilles in terms of their proficiency. Demographic research on heritage populations is critical to a deeper understanding of heritage language acquisition. This is a perfect example of a research topic that could benefit greatly from interdisciplinary engagement that pools different types of expertise.

${ }^{9}$ Were linguistic theory to focus exclusively on monolingual speakers, much linguistic territory would be off limits, since many languages no longer have monolingual native speakers. Consider for instance Basque and Catalan: every speaker of these languages knows Spanish as well. Arabic, also, is notably prevalent in predominantly diglossic contexts, as are many minority languages around the world. We would even venture to guess that a large number of valuable grammars and linguistic descriptions and analyses are already based on data from non-monolingual speakers.
} 
(1) Should the linguistic theory developed for monolingual language be applied to bilingual and multilingual phenomena?

(2) Is the competence of heritage speakers (and other kinds of bilingual speakers) different from the competence of monolingual controls?

Answering both of these questions calls for a combination of assumptions, data, and analysis. We have advocated collecting more data to inform the answers; we ourselves and our reviewers have tried various analyses (which in turn call for more data). This response is an appropriate place to articulate our assumptions.

With respect to (1), we support the starting assumption that the same linguistic theory, whatever its ultimate form, should fit both sorts of data. Assuming otherwise (as is proposed by some researchers, e.g., Myers-Scotton 2002) strikes us as worrisome-it limits the theory in an unnecessary way and it also imposes an almost impossible constraint on data collection: we would need to look for people who have been exposed to just one language and, ideally, avoid even bidialectal speakers (for Arabic at least, that becomes an impossible task). This is reminiscent of the traditional practice among dialectologists to concentrate on more dialectal, non-standard, even archaic forms of language - the ones that were obligingly provided by the famous NORMs ("non-mobile old rural males"), the ideal dialectal informants (see Chambers and Trudgill 1998: 29-30, 145). The argument that dialectologists used to abandon the NORMs is as follows:

"At the turn of the 21st century, there are new prospects for the study of dialect syntax. These are primarily due to developments outside dialectology, more exactly in linguistic theorizing. What is responsible for the currently observable rise of dialect syntactic research in several European countries is, in the first place, a broadening of the perspective in recent generative theory and language typology. No longer is it cross-linguistic variation only that matters. Variation within individual languages, too, is increasingly attributed important theoretical 
significance. ${ }^{10}$ One of the consequences of this is that a strong need is felt to improve the empirical basis for reliable descriptive generalizations and for drawing conclusions for linguistic theory. In other words, due to the rising interest in variation across dialects within generative linguistics and language typology, we are witnessing a period in which a much improved data situation will allow us to make substantial advances in exploring dialect grammar and integrating the findings into a larger theoretical frame." (Kortmann 2002: 185)

One could easily replace the word 'dialect' with the word 'heritage language' and successfully apply the same argument to heritage speakers. The fact that our commentators generally agree with this premise is very encouraging. And so the answer to (1) is 'yes': testing the current linguistic theory on new populations is something that we should all aspire to. The appeal of heritage speakers lies in their ubiquity - they are young and healthy, they are eager to participate in studies, they are numerous enough to allow us to test new tools (corpora, experimental designs, micro- variation), and they are increasingly accessible. That makes them no less desirable a population than speakers of creoles, sign languages, or endangered languages in "exotic" locales.

Answering 'yes' to question (1) above allows us to avoid theoretical straightjackets. But it also prompts a further question, which we would like to raise here but are not ready to answer (see also Lohndal's commentary):

(3) Is the linguistic theory developed for monolingual language adequate to account for bilingual and multilingual phenomena?

An honest answer to this question is "we do not know". The best way to discover the answer is by exploring more phenomena in the heritage domain and in other domains where more than one language is at play. One can approach this in two

\footnotetext{
${ }^{10}$ Variation within individual languages and language families has of course a long history within the field of dialectology. This type of variation has recently gained attention within the Principles and Parameters framework, particularly within research on comparative syntax and microvariation (Kayne 2010, 2013) and clausal and phrasal cartography (Cinque and Rizzi 2010).
} 
ways. From a top-down perspective, we can use the theory to predict which aspects of grammar are likely to be resilient and which may be subject to change. Proceeding bottom-up, we have to start by admitting that there is no way of knowing in advance what kinds of data are ultimately going to be interesting in the heritage domain: this approach therefore calls for more descriptive work in this area. The two approaches need to continue checking in with each other to guide us in answering the question in (3).

A guiding principle of the top-down approach has been the expectation that phenomena which are located in a particular component of grammar will be more resilient than phenomena that are mediated by more than one component (hence the Interface Hypothesis, as explicated in the work by Sorace and her colleagues). ${ }^{11}$ Interface phenomena may be more prone to change because mapping between components is not always isomorphic. For example, intonational phrasing does not perfectly track syntactic phrasing. Similarly, discussions of various phenomena within Optimality Theory (Bresnan 2002, Perlmutter 1998) and Distributed Morphology (Halle and Marantz 1993, Embick and Noyer 2001) have shown that syntactically expected forms may be prevented from surfacing because of the requirements of another component or module. Theories differ as to how correspondences between components are handled (Jackendoff 1997), but the general lack of isomorphism in these mappings is not controversial.

It may not be surprising that interface phenomena should place a greater burden on a speaker's linguistic knowledge than do phenomena which are internal to a single component. The proper use of interface phenomena presupposes mastery of the relevant components and their primitives, processes, and constraints; additionally, as we have

\footnotetext{
${ }^{11}$ One challenge faced by the field (in all its theoretical incarnations) is the task of distinguishing component-specific phenomena from interface phenomena and from phenomena which are independent of language altogether. Within the Principles and Parameters framework, an ongoing research task is to determine core aspects of language that are not reducible to any other component or faculty.
} 
already mentioned, mapping mechanisms or correspondence rules may deviate slightly from, or even alter, their output. Let us compare word order and agreement. Word order is usually relatively resilient in heritage speech, as it is in first language acquisition: children converge on the word order of their language early in the acquisition process. Although processes that alter word order may take longer to master, children typically acquire the basic phrase structure of their language (for example, the relative order of the verb and its complement) by two years of age. This ability is preserved in heritage speech. In fact, even the order of functional categories is relatively resilient among heritage speakers. Albirini and Benmamoun (2013) show that Egyptian heritage Arabic speakers, who are also native speakers of English, place negation in its appropriate position above the TP phrase, even though this is a different ordering from the one usually posited for English (Pollock 1989). Their performance on processes that involve the morphological interaction between negation, tense, and the predicate, however, is markedly worse than their performance on sentential negation. The same pattern holds for agreement relative to word order. For example, heritage speakers have no problems producing the correct adjective-noun order, but they frequently struggle with the concord relation between the adjective and the noun, despite the fact that the paradigms are relatively small and the features relatively simple (when compared to verbal paradigms and agreement features on verbs). Likewise, heritage speakers tend to place the subject in the appropriate position in the clause as sanctioned by the language's phrase structure rules and word order constraints. On the other hand, the agreement relation between the subject and the verb displays some vulnerability based on linearity and adjacency; these are clearly interface effects that have to do with the mapping to PF.

Let us now turn to the second main question introduced above: Is the competence of heritage speakers (and other kinds of bilingual speakers) different from the competence of monolingual controls? Answering this question is important not only for theory but also for our understanding of what (if anything) makes heritage speakers 
special. This issue was raised particularly strongly in the commentaries by Meisel and de Swart, who do not think that heritage speakers are different from any other kinds of bilinguals. At the very least, they contend, the empirical generalizations offered in this line of research to date have not added new information about the nature of linguistic knowledge that was not already known from research on monolingual or bilingual speakers.

We do not have a full answer to the question of what if anything makes heritage speakers special, but we would like to offer at least some initial considerations. First of all, compared to native controls, heritage speakers are more ready to rely on basic principles of language design unencumbered by additional semantic or contextual factors. They show full compositionality in their use of language and they often rely on general grammatical principles (for example, subject preference in the interpretation of relative clauses - see Polinsky 2011). In section 2.2, we will show that a similar reliance on basic grammatical principles informs their grammar of case and agreement. The second consideration, one that has not taken center stage in this volume, has to do with the parallels between heritage language and second language. Unlike balanced bilinguals, heritage speakers have some properties resembling L1 speakers and some reminiscent of L2 (see Montrul 2008). Heritage speakers are significantly faster than L2 speakers in (re)learning their home language as adults (Davidson and Lekic 2012), which again indicates their special status.

\subsection{Using heritage language to test theory}

Our paper advanced the notion that the resilience of tense (relative to Case and agreement) arises from the fact that tense is syntactically pervasive: it licenses subjects and enters into dependency relations with the complementizer and predicate layers. In his commentary, Soltan takes issue with this idea, and advances the plausible alternative that 
tense may be relatively resilient because it is a substantive category in the sense of Chomsky (1995), while case and agreement are not. It is of course not clear in what sense tense, as a functional category, is substantive. Tense is closely related to aspect, which we have shown to be vulnerable in heritage language grammars. Thus, if there is a sense in which tense is substantive, one would have to assume that this substantivity does not extend to aspect. This possibility seems ad-hoc to us. Soltan rightly points out that case is also critical to syntax, as evidenced by the fact that languages with rich case morphology allow a greater degree of word order freedom than those with impoverished case systems. However, we believe that the vulnerability of case has more to do with how it is realized, with structural case being more vulnerable than inherent case. In other words, what is vulnerable is the mapping from syntax to morphology of the case that is not semantically grounded. No such distinction exists in the context of tense, because there is no inherent vs. structural tense dichotomy. All tense morphology is inherent, since it is all semantically grounded.

Soltan also questions the thesis advanced in our paper that agreement is relatively more robust than case, an observation which we took to indicate that the connection between case and agreement is completely severed, or at best weakened, in heritage languages. The implicit assumption that seems to be driving Soltan's skepticism is that there is an intimate relation between case and agreement. This is an important assumption within minimalism which is actually a resurrection of approaches from the early days of the Government and Binding framework (Chomsky 1981). However, it does not seem to us that the connection between case and agreement has been well established within minimalist theory. The motivation for the proposed connection seems to be that, in order for some categories (usually functional and lexical categories that carry a particular set of formal features) to enter into dependency relations, we need some mechanism to connect them. That mechanism is the relation Agree, which echoes the traditional agreement relation, but also goes beyond it. Not all Agree relations involve the presence of 
traditional agreement features; consider the relation between negation and a subsequent negative element (Zeijlstra 2008, Haegeman and Lohndal 2010) or between + Wh $\mathrm{C}$ and a wh-phrase (Chomsky $2001 \mathrm{a}, \mathrm{b})$.

In fact, strong evidence exists that there is no connection between case and agreement. For example, in Standard Arabic, nominative case can be licensed by a tensed negative, while agreement is realized on the verb (Benmamoun 2000):

$$
\begin{array}{lll}
\text { lam } & \text { ya-Ptii } & \text { 1-walad-u. } \\
\text { NEG.PST } & \text { 3MASc-come.3MASC } & \text { the-boy-NOM }
\end{array}
$$

'The boy did not come.'

In (4), tense is realized on negation and agreement on the verb, but this disparity does not seem to prevent the case dependency. Of course, one could argue that the Agree relation between Tense on negation and the subject is abstract, but that be would ad-hoc, especially in a language that has a rich overt agreement system.

Additional evidence in Arabic for severing the relation between tense and agreement comes from so-called verb-less sentences, where nominative is available in the complete absence of agreement:

$$
\begin{aligned}
& \text { Pal-walad-u fi-l-bayt-i. } \\
& \text { the-boy- NOM in-the-house } \\
& \text { 'The boy is in the house.' }
\end{aligned}
$$

There is strong evidence for the presence of tense in (5), but no evidence for the presence of agreement. Here again we find structural case that is totally independent of agreement. 


\subsection{Alternative analyses of the heritage data presented in the position paper}

It is one thing to discuss the theoretical significance of new data in an abstract and general way, and it is another thing to actually provide competing analyses for novel data; the more new analyses are put forward, the less we will need to make abstract arguments for the utility of heritage data. Two of our commentators have actually engaged in providing such competing analyses, and we would like to discuss these analyses in this section. The analyses focus on three phenomena: construct state, agreement vs. concord, and aspect. We will take up each of these topics in turn. All three phenomena represent difficult issues in linguistic theory, and we find the use of heritage data in their discussion a welcome development.

The status of the Arabic construct state is addressed in Soltan's commentary. ${ }^{12}$ This construction is illustrated by the Moroccan Arabic example below:

$$
\begin{aligned}
& \text { ktab 1-wəld } \\
& \text { book the-boy } \\
& \text { 'the boy's book' }
\end{aligned}
$$

Though ktab is interpreted as definite, it cannot carry the definite article; however, adjectives modifying it must. Benmamoun (2000) argues that the two members of the construct state form a prosodic unit in PF (essentially a single word), and that for this reason, the definiteness marker may be spelled out only once, at the PF interface. The discussion in our paper concerned the fact that heritage speakers of Arabic often double the definiteness marking on these structures, producing the pattern Def-N+Def-N.

As Soltan observes, a similar (grammatical) construction exists in Egyptian Arabic, in which two (adjacent) nouns in a "made of" relationship both carry the definiteness marker (Def-N+Def-N). Soltan's example below is a good illustration ${ }^{13}$ :

\footnotetext{
${ }^{12}$ A survey of the ongoing debate about the construct state is provided in Aoun et al. (2010). For a discussion of the construct state in Hebrew, see Borer (1996), Ritter (1988).
} 


$$
\begin{aligned}
& \text { Pil-xaatim Pil-dahab } \\
& \text { the-gold the-ring } \\
& \text { 'the gold ring' }
\end{aligned}
$$

However, as Albirini and Benmamoun (in press) show, this type of construction is ungrammatical in Palestinian Arabic. The (non-heritage) Palestinian speakers consulted in their study overwhelmingly found the Def-N+Def-N pattern to be ungrammatical. So, there seems to be a principled difference between Egyptian and Palestinian Arabic with respect to such structures. ${ }^{14}$ Furthermore, in genuine construct state contexts, if both nouns carry the definiteness marker the resulting construction is ungrammatical, yet heritage speakers produce it anyway - thus, our main point remains intact. Below, we reproduce one instance of the original heritage data from our position paper (BPM) and provide an additional example from the corpus used by Albirini and Benmamoun for their study:

$$
\begin{aligned}
& \text { 1-bayt r-raPiis } \\
& \text { the-house the-president } \\
& \text { 'the president's house' } \\
& \text { 1-handasat 1-kumbyutraat } \\
& \text { the-engineering the-computers } \\
& \text { 'computer engineering' }
\end{aligned}
$$

In (8) and (9), there is no "made of" relation, yet the heritage speakers attach the definite article to both members of the construct state, which is not allowed by the rules of construct state formation.

The question, then, is whether this is an interface issue, as we claim in this paper. Soltan suggests an alternative: heritage speakers attach the definiteness marker to both

\footnotetext{
${ }^{13}$ This construction may be a reduced relative, but we will leave its internal structure aside for the present purposes.

${ }^{14}$ The intended meaning in Palestinian Arabic and other dialects, such as Moroccan Arabic, can be expressed via adjectival modification or relativization.
} 
nouns because that is what they do in the free state (which involves a preposition). In other words, they extend the free state pattern to the construct state. This possibility cannot be discounted, especially if we find that the free state is more frequent than the construct state (although this makes us wonder why heritage speakers would continue to use the construct state, instead of simply relying on the free state).

The next point we would like to bring up has to do with agreement and concord, also discussed by Soltan in his commentary. Soltan correctly points out that naayem in example (30) in our position paper (reproduced as (10) below) should be glossed as a participle and should not be specified for person.

$$
\begin{aligned}
& \begin{array}{l}
\text { El-walad wi-l-kalb } \\
\text { naayem }
\end{array} \quad \begin{array}{l}
\text { Sala } \\
\text { the-boy and-the-dog } \\
\text { sleep.3sG.M }
\end{array} \text { on the-bed } \\
& \text { 'The boy and the dog are sleeping on the bed.' (Heritage Egyptian Arabic) }
\end{aligned}
$$

This was a descriptive inaccuracy, and we are grateful to Soltan for pointing it out. However, this does not fundamentally affect the analysis, since the participle is the main predicate of the sentence and enters into a typical subject-predicate relationship. The only difference between the gloss we provided and the correct participial interpretation is that person agreement is absent from participle agreement but gender and number agreement are present.

Soltan suggests that the observed pattern maybe a case of concord rather than close conjunct agreement. Concord is usually reserved for agreement within the nominal domain in Arabic and other languages. ${ }^{15}$ For example, in almost all Arabic varieties, nouns and adjectives agree in number, gender and definiteness (and Case in Standard

${ }^{15}$ But see Baker (2008, 2011), where predicate-adjective agreement, or concord, is argued to involve the same mechanism as verb agreement. For Baker (2011), the main difference has to do with the location of the agreement controller (or goal) relative to the target of agreement (or probe). 
Arabic). However, it is unlikely that we are dealing with a case of concord in (10). First, there is no agreement with the definite subject preceding the participle, as we would expect under a concord relationship. Second, the subject and the participle clearly do not form a nominal cluster, or what Soltan refers to as a "syntactic category containing both the conjoined subject and the participial predicate," which is the usual domain for concord. The consensus within Arabic syntax is that a preverbal subject is more prosodically demarcated from its predicate than a postverbal subject is, and thus it is unlikely for the subject and predicate to form a cluster. ${ }^{16}$ In the original corpus used by Albirini and Benmamoun (in press), there are clear instances of verbs that do not enter into concord relations, but seem to enter into close conjunct agreement as in (11).

$\begin{array}{ll}\text { L-walad we l-kalb raah } & \text { barra. } \\ \text { the-boy and the-dog went.3sG.M } & \text { out } \\ \text { 'The boy and the dog went out.' } & \end{array}$

In sum, while there are many possible explanations for the fact that an intended agreement pattern fails to surface (Preminger 2011a, 2011b, Bock and Middleton 2011), interface or performance factors are particularly likely reasons for such a failure. This is especially true when the agreement controller and its target are in a specifier-head relationship, since this is considered the strongest context for agreement to surface (Franck et al. 2006). If our conclusion is correct, agreement is a promising area from which to probe (no pun intended) interface phenomenon in heritage grammars.

Let us now turn to Slavic aspect. In her commentary, Borik analyzes aspect in heritage Russian as discussed by Laleko (2010) and proposes an alternative to Laleko's analysis. The main objection raised by Borik against the approach undertaken in Laleko

\footnotetext{
${ }^{16}$ See Aoun et al. (2010) for an overview of different analyses of the status of the preverbal subject in Arabic. None of the surveyed analyses suggest that the subject and the predicate it precedes form a cluster that would constitute a domain of concord.
} 
(2010) is that the link between telicity and perfectivity introduced at the VP level seems to be "closer-than-necessary". This criticism follows directly from Borik's own theoretical standpoint, argued for at length elsewhere (Borik 2006), that telicity and perfectivity are always independent of each other and "should never be collapsed together" (Borik 2006: 4). While this rather extreme position has been expressed previously in the literature on aspect, it is certainly not uncontroversial, as evidenced by the rich body of work in which the opposite view, that telicity and perfectivity are inseparable, is presented (see for example Filip 2008, 2011, 2012, and references therein). Whatever the ultimate consensus among aspectologists turns out to be (if indeed we ever live to see one), it seems that until there exists a single and universal approach to analyzing the nature of the relationship between telicity and perfectivity, any work in an understudied field like heritage linguistics should be cautious of the more extreme theoretical views, particularly those that have not been justified or even tested experimentally with native speakers. In this regard, Laleko's (2010) integrated approach presents an appealing position that not only reconciles the extreme views on aspect, but also yields a theoretical model that accurately captures the empirical facts obtained from a control group of native speakers.

Borik further objects to our applying the notion of 'totality' in the description of perfectivity, and provides examples in which the concept of 'actual endpoints' arguably does not apply to the characterization of perfectivity. The two examples given in her commentary represent a special class of the Russian perfective prefixes (pro-, po-). These prefixes receive a separate discussion in Laleko's work (2010: 220-224); she characterizes them as aspectual markers that perfectivize atelic predicates by adding an 
external temporal boundary to an event. This boundary can serve as an actual end point for the relevant time interval, making it possible to maintain the 'totality' view of perfectivity against which Borik objects (see also Verkuyl 1999, 2012; Dickey 2000 for additional discussion).

As far as we can tell, Borik's analysis is not radically different from the one offered in Laleko (2010). It seems to essentially restate the original proposals in Laleko (2010), most notably the idea that advanced heritage speakers have difficulty with imperfectives in precisely those contexts that give rise to an aspectual competition in the baseline grammar. Such contexts are the ones in which imperfective marking is determined by contextual cues and pragmatic inferences rather than by semantic operators (Laleko 2010: 171-189; 210-211). Borik's account appeals to the very same notion of aspectual competition proposed by Laleko to explain the problematic cases, and essentially seconds Laleko's (2010) claim that the general-factual imperfective is lost in heritage Russian because its interpretation is determined by pragmatic factors, rather than semantic entailments. The difference between the two analyses is mostly terminological. For example, Borik uses different terms to describe the distinction between the pragmatic and semantic functions of the imperfective ("truth-conditional" and "non-truthconditional," respectively).

Borik concludes her discussion with the proposal that "[t]he first part of the aspectual dichotomy that disappears [for heritage speakers] is the part which does not influence the truth-conditions of a sentence" (p. 8). But this idea follows directly from the implicational model of aspectual restructuring in heritage languages discussed in Laleko (2010: 245), in which it is hypothesized that control of pragmatically-determined, 
discourse-dependent aspectual functions requires a higher level of language proficiency than does the knowledge of sentential aspect modulated by semantic operators. Whether or not this proposal turns out to be on the right track is a question for future research. Recent studies have offered encouraging results that point to unequal difficulty associated with phenomena mediated at the syntax-discourse interface compared with phenomena mediated in narrow syntax and semantics (Laleko and Polinsky in press).

\section{$3 \quad$ Theory of language attainment}

Assuming that heritage grammars are internally consistent, it is important to understand what forces shape these grammars. The issue of attainment in heritage speakers was raised by several commentators (Meisel, Kupisch, Soltan, Dąbrowska, and de Swart): are the gaps we find in heritage grammars the result of attrition, incomplete acquisition, or something else? Although there may be heritage speakers who are very fluent and native-like in their heritage language, the vast majority of the speakers we focused on were not fully fluent. Such speakers differ in their pattern of attainment from several relevant control groups: (i) the parental generation; (ii) fluent bilinguals of the same languages; and (iii) native speakers in the home countries (matched for age and socio-economic status). The question we need to ask is why the grammar acquired by these speakers differs, sometimes significantly, from the target grammar. Some of the differences between heritage grammars and target grammars that we discussed in our paper are the result of what we and other researchers call 'incomplete acquisition'; others may result from attrition caused by insufficient input and use of the heritage language. 
Meisel reasonably asks what it means, theoretically speaking, for a grammar to be incomplete. Before we respond to this question, we wish to address an issue of terminology. Although in many publications we have referred to heritage grammars as "incomplete", we wish to discourage use of the holistic term "incomplete grammar", because it invites misunderstanding and raises a number of theoretical and sociopolitical problems. We obviously do not mean to imply that heritage speakers' grammars are deficient, and we worry that the term "incomplete grammar" may turn into a value judgment about the languages of ethnic minorities (see discussion in Otheguy and Zentella 2012). We prefer to characterize the grammatical systems of heritage speakers as "divergent" from the target in systematic ways, and we are interested in tracing the roots of this divergence. We do maintain that divergent heritage grammars often arise due to insufficient exposure to the target language; in other words, we support the notion of incomplete acquisition as a process, but want to discourage the use of the term "incomplete grammar" to describe the end result of the process. Heritage grammar is not incomplete grammar: its users employ a regular system to produce various patterns, although the forms of those patterns may differ from those found in the non-heritage language. We believe the term "divergent" grammar is a more neutral and appropriate term to describe this situation.

So what does it mean for a grammar to be divergent (or incomplete)? Most of the studies we reported on in our paper involved adult subjects, whose childhood language learning period and process we attempted to reconstruct. We know that as children, these speakers were either simultaneous or sequential bilinguals, and we know that the vast majority ended up with a grammar that diverged, often in significant ways, from the 
target. Either these speakers failed to fully attain the target grammar during childhood (incomplete acquisition), or they lost their mastery of various aspects of the target grammar as children or adults (language attrition).

Language attrition is language loss at the individual level. For a grammatical property to be lost, it must have been acquired, mastered, and retained as part of the speaker's knowledge for a while. Subsequently, likely as a result of fluctuations in input, errors began to emerge. It is easy to test language attrition in adults, since they may be assumed to have reached full linguistic development of their first language. We also know that language attrition in adults is relatively minor, and tends to affect lexical retrieval and fluency more than the integrity of the grammar itself (Schmid 2011, Montrul 2008).

Children can also undergo attrition, and when they do, the effects on the linguistic system are much more dramatic: children may forget core aspects of grammar, like morphology and syntactic structures, in addition to vocabulary. It is also true, however, that different grammatical properties have different maturational schedules, as Meisel reminds us with respect to the critical period and age of acquisition (AoA) effects. Thus, while some properties of language, such as word order or pro-drop, are acquired very early, other aspects of complex syntax and semantics take much longer to develop (subjunctive, binding properties, relative clauses, passives, conditionals, complex nominals, etc.). Thus, if a child does not get sufficient input and exposure to develop these structures in spoken language and does not receive schooling in the language, it is very possible that these properties will not develop to an age-appropriate level (Dąbrowska and Kupisch's commentaries both make this point; see also Schaufeli's 
quote earlier). This failure to attain an age-appropriate grasp of all points of the target grammar is what we intend by the term 'incomplete acquisition'.

We have acknowledged in several publications that the best way to test attrition and incomplete acquisition is by doing longitudinal studies, but we have not actually conducted any. We have, however, attempted to tease apart incomplete acquisition from attrition experimentally by undertaking cross-sectional studies comparing child and adult heritage speakers (Montrul and Sánchez-Walker 2013, Polinsky 2011), or adult heritage speakers and monolingual children (Chung 2013). There are at least three shorter-term longitudinal studies of Spanish heritage speakers in the United States that we know of, which clearly show that it is possible to document both attrition and incomplete acquisition in these speakers even during childhood.

Merino (1983) presents a study of school-age Latino children in California. The children were tested on production and comprehension of early- and late-acquired morphosyntactic properties of Spanish (tense, agreement, gender, subjunctive, relative clause, conditionals). The study included a cross-sectional study of children from kindergarten to $5^{\text {th }}$ grade, and a longitudinal study that followed up with the original kindergarten children two years later. Although Merino shows only group results, this study provides clear evidence that attrition occurs when children do not receive academic/formal instruction in their heritage language. As accuracy on English comprehension and production increased in Merino's subjects over time, their use of Spanish decreased, and their production and comprehension accuracy on complex structures (subjunctives, relative clauses, conditionals) attrited accordingly. Anderson (1999, 2001) presents a longitudinal study of two siblings from Puerto Rico who 
immigrated with their parents (both professors) to the United States when they were 2 and 4 years old, respectively. The siblings were followed longitudinally beginning two years after their immigration, at ages 4 and 6 , respectively, and the recordings ended when the sisters were 6 and 8 years old. Based on the ages of the children upon arrival to the United States, we can assume that the older sibling, who was 4 years of age on arrival, had already developed basic Spanish and became a sequential bilingual, whereas the younger sibling, who was only 2 years old on arrival, started to develop English before age 3 , and thus may be considered a simultaneous bilingual. Anderson analyzed the siblings' evolution of gender agreement, tense, and mood in Spanish. She shows that the older sibling had native-like command of these properties at age 6 (two years after arrival), with $100 \%$ accuracy on gender agreement and only a $2.4 \%$ error rate on past tense and mood. By age 8 , however, she showed an increase in error rates to $5.8 \%$ in gender agreement and 5\% in verbs, a sign of attrition. By contrast, the younger sibling was already making errors at age 4 (8.5\% with gender and 3.8\% with tense and mood) monolingual Spanish-speaking children use these forms with $100 \%$ accuracy by age 3 . Two years later, at age 6, the younger sibling's Spanish abilities in the areas studied had worsened considerably: her error rates were now $18.6 \%$ for gender and $13.9 \%$ for verbs, a threefold increase. This study illustrates incomplete acquisition and attrition by a younger child (a simultaneous bilingual) and attrition in childhood by an older child (a sequential bilingual).

Most recently, Silva-Corvalán (2014) is large-scale longitudinal study of her two grandchildren, Nico and Bren, from the ages of 1 to 6 years old. Nico was the older sibling. The two siblings were simultaneous bilinguals, born in the United States to a 
Spanish-speaking father, and a monolingual English-speaking mother. (Since SilvaCorvalán is a first-generation immigrant to the United States, her grandchildren are thirdgeneration immigrants). The children received input in Spanish from their father and grandmother. The father used Spanish with Nico almost exclusively until the child was 3;6 years old, but use of Spanish decreased from that age because Nico preferred to speak in English with his parents. Bren, the younger sibling, heard relatively less Spanish from his father, but in child-directed speech the father used Spanish almost exclusively with Bren until he was about 3;0 years old. The children spoke almost only English with each other and occasionally responded in English to their father before age 3;0, but addressed him in English more and more frequently after this age. Silva-Corvalán (2014) analyzes several properties of these children's English and Spanish, such as their use of subject pronouns, verb tenses and copulas. Like the European researchers mentioned by Kupisch and Meisel, Silva-Corvalán found evidence that the children used separate linguistic systems for their two languages from the beginning of the acquisition period, although interaction occurred between the two. Nico and Bren attained monolingual-like knowledge of English, and they also attained monolingual-like knowledge of numerous syntactic structures and the less complex verb tenses in Spanish. For example, they showed native-like acquisition of gender agreement by age three. Nico's knowledge of the conditions on subject realization and placement, of ser and estar, and of some of the more complex tenses showed more stability than Bren's; however, both children's grammars differed from the one underlying the Spanish input they had been exposed to. Silva-Corvalán shows that around the ages of $3 ; 6$ to 4;0, when their exposure to English had increased considerably and their exposure to Spanish was lessening, the siblings 
began to diverge from typical monolingual development in the domains of Spanish subject realization and placement, in some aspects of the Tense-Mood-Aspect (TMA) system, and in the production of lexical complexes. Compared to the adult model that Silva-Corvalán also studied, the siblings evidenced incomplete acquisition of some aspects of Spanish. Bren, for example, did not develop the pragmatic distribution of subjects in Spanish, unlike monolingual children, and both children showed incomplete mastery of the subjunctive. In the case of Nico, the subjunctive suffered attrition; in the case of Bren, it did not develop.

Although the study ended when the siblings were six years of age, Silva-Corvalán was able to trace similarities between her grandchildren's grammars and the grammars of adult heritage speakers of Spanish whom she worked with many years earlier (SilvaCorvalán 1994). The adult heritage speakers were of Mexican origin, and lived in an immigrant community in Los Angeles. Although Nico and Bren were exposed to Chilean Spanish and grew up in a professional family rather than an immigrant community, the patterns Silva-Corvalán found in her grandchildren and in the Mexican-American adults are strikingly similar. Compared to first-generation immigrants, the siblings and adult heritage speakers who did not receive formal education in Spanish showed an increased production of overt subject pronouns and preverbal subjects, and a reduced TMA system. Furthermore, the young siblings and the adult heritage speakers preferred to mark possession with a possessive adjective, as in English, rather than using an article and a clitic pronoun, as preferred in Spanish.

Although the three longitudinal studies discussed in this section all focus on Spanish in the United States, they represent different dialects (from Puerto Rico, Mexico, 
and Chile), different types of bilinguals, different families, different socio-economic levels, and different parental education levels. Given these differences in background, the similarities found in the structural outcomes of these speakers' language development are striking. Most importantly, Silva-Corvalán was able to seamlessly link her work on the Mexican American community, conducted within a sociolinguistic perspective, to a psycholinguistic study of bilingual language development in two Chilean American children. We have argued above for an integration of these two types of approaches.

We have established that a lack of sufficient input results in incomplete acquisition among heritage speakers, but what constitutes (in)sufficient input? Meisel, Kupisch and Dąbrowska make the fair criticism that, although we claim that insufficient input is one of the main factors leading to the structural changes observed in heritage grammars, we have been vague in describing what 'sufficient input' would actually entail. The problem with input is that it is easy to estimate vaguely, but difficult to actually measure. When we say that a speaker has had insufficient input in a language, we mean not only that (s)he has been exposed to the language infrequently, but also that that exposure has occurred in restricted contexts. For example, most heritage speakers are exposed to their heritage language at home in familiar contexts, and do not receive schooling in the language. As Dąbrowska points out, this restriction on the context of exposure deprives young speakers of the opportunity to develop literacy and academic language, to expand their vocabulary, and to learn a different register where other more complex structures may be common. Insufficient input may also be a product of the family environment, the size of the heritage language community, and the public presence of the language beyond the home. The number of conversational partners a child 
has varies from situation to situation, providing us with another way to estimate quantity of input. In some families, both parents speak and transmit the heritage language; in other families, there is only one fluent speaker (Silva-Corvalán 2014). In yet other families, the parents may speak two different native languages, so the child may be exposed to two heritage languages at home in addition to the majority language outside the home, or there may be other heritage language-speaking family members or caregivers who are also part of the social network of the child (Silva-Corvalán 2014). Meisel also suggests a case where one of the parents is a second-language speaker of the heritage language who happens to be transmitting a non-native variety to the child; however, we are not aware of any studies documenting this possibility.

Meisel puts the question of input very pointedly: what specific quantity of input is minimally sufficient for children to master different properties of the target grammar? We know that bilingual children who are exposed to $50 \%$ input in two languages develop full acquisition of both target grammars (at least in early childhood) - but what is the exact exposure threshold below which a grammatical structure will fail to develop? Unfortunately, we do not have the answer to this question, although we would like to find out.

Dąbrowska's commentary also links the issue of frequency of exposure to the context of written language. Input frequency is typically estimated from corpus studies. When investigating the diachronic development of the V2 phenomenon in the history of English, for instance, Lightfoot (1991) lists specific frequencies of structures appearing in his source texts. He postulates that a change in the frequency of a certain structure indicates a change in the input for new speakers, and will coincide with the emergence of 
new structures. Yang (2002) provides a computational model of the input frequencies needed for a child to select the correct grammar from the input and set parameters accordingly, in the face of other competing grammars. It would be ideal to develop a computational model or other method to estimate the minimum input threshold needed to develop target-like mastery of different properties of a language and the critical threshold needed for maintenance; however, this is beyond the scope of this response.

In addition to quantity or amount of input, quality of input for heritage speakers is another important consideration. This issue was raised by Meisel, Muysken, Dąbrowska, and Kupisch. Could it be the case that heritage speakers are not exposed to the same variety of the heritage language as monolingual speakers growing up in a monolingual setting? Here, the possibility exists that the language variety spoken by heritage speakers and their parents is different from the standard language. In fact, many Turkish speakers in Europe and Spanish speakers in the Unites States come from rural regions of their home countries, and may speak rural varieties of their languages. It thus becomes important to determine whether the rural varieties and the standard varieties differ in the grammatical features under investigation (gender agreement, case marking, relative clauses, subjunctive, etc.). It is even possible that the language of the parental generation itself may have undergone changes in some areas. This possibility has recently been confirmed by two studies: Montrul and Sánchez-Walker's (2013) study of differential object marking (DOM) in Spanish, which spanned two generations and compared transnational communities, and Otheguy and Zentella's (2012) study of overt subject expression in New York City Spanish, which found evidence of dialect leveling. Furthermore, Montrul, Bhatt and Girju (submitted) have found that first-generation 
Spanish-speaking immigrants from Mexico show some of the same patterns of DOM omission as heritage speakers do, but that Hindi and Romanian first-generation immigrants to the United States show no attrition and are no different from speakers of Hindi and Romanian tested in India and Romania. Once again, what we find in one population, one language, and one setting may not be generalizable to other settings. These possibilities need to be investigated in a wider variety of contexts in order for us to gain a richer understanding of the issue.

Finally, Kupisch raises a question that we think represents a crucial piece of the puzzle in understanding the outcome of heritage language acquisition, especially when attempting to incorporate findings from proficient bilingual children in Europe with those of adult heritage speakers in the USA. Is it possible that around school age, when many children start attending monolingual schools in the majority language, certain linguistic properties are not yet part of their internalized knowledge, even though performance of these properties may be witnessed in their speech? Based on our knowledge, we believe that the answer to this question is definitely yes, especially in the United States, where language attitudes and English-only policies work against the promotion of educational programs to support heritage languages; in fact, this may be a critical difference between the U.S. and European contexts of language learning. The studies reported by Kupisch on French-German bilinguals are particularly interesting in this context.

Interestingly, Dąbrowska's commentary on our paper offers an intriguing insight on the question posed above: she suggests that those adult heritage speakers who show high proficiency in their heritage language are precisely those who happened to benefit from schooling in their heritage language. We concur with Dąbrowska that heritage 
languages offer a unique opportunity to investigate the impact of schooling and written language on linguistic development; this issue that has not been investigated to date with this population, and is an important area for future research.

\section{Methodology}

The main objective of our keynote article was to give a very general picture of recent research on heritage language conducted within the theoretical and psycholinguistic traditions, and we pulled together evidence from different studies, different languages, and different groups of heritage speakers to do so. All our colleagues have raised important issues regarding methodological considerations, and we largely agree with all the issues raised. As suggested by de Swart, in order to arrive at a more precise account of the heritage language linguistic phenomena, it will be necessary to focus on the individual and his/her variable language use patterns. Indeed, the testing of hypotheses regarding developmental mechanisms and potential acquisition failure requires a level of analytical detail that is difficult to achieve in studies that emphasize group averages and obscure crucial differences among individuals and their backgrounds.

While we would like to approach the study of these speakers from an experimental and theoretical perspective, the wide variability of this population presents formidable challenges for research. Any two speakers are likely to have different language learning histories, to speak slightly different varieties of a language, to have different levels of education, and to vary in terms of age of immigration or onset of acquisition of the majority language, among other things. As a field, it is important that we understand these challenges and do not shy away from them. We sympathize with de 
Swart's suggestion that it is time to embrace this variability and develop research designs and statistical tools that allow us to understand and measure the range of data available. We also agree that there is room for improvement in future experimental studies of heritage speakers, and that a host of internal and external variables need to be carefully controlled if we are to gain a deeper understanding of the factors that play a role in the grammars of heritage speakers.

Meisel makes the point that, at a minimum, every study of heritage speakers needs to describe the participants in detail and be very specific about the language learning history of these individuals. We concur with this assessment. Age of onset of bilingualism (AoA) in particular is a crucial variable that defines many types of bilinguals, and as Meisel correctly points out, not all studies of heritage speakers to date have controlled for this variable carefully and consistently. However, even when this variable is controlled for, we can still arrive at different results depending on the phenomenon studied. For example, in Montrul's (2002) investigation of Spanish heritage speakers' interpretation of preterite and imperfect, AoA was carefully controlled for. The study included simultaneous bilinguals, sequential bilinguals with early L2 onset, and sequential bilinguals with later L2 onset (these speakers had received schooling in their native language in their countries of origin). According to the results of this study, the late arrivals did not differ from the adult monolingually raised native speakers, whereas the other two groups did. The simultaneous bilinguals - those who received less exposure to Spanish-were the most inaccurate of all the groups. In this study, AoA was a highly relevant factor. On the other hand, Montrul and Sánchez-Walker (2013) also examined simultaneous and sequential heritage speakers of Spanish, both adults and children, on 
their knowledge of DOM. In this study, AoA did not make a difference: simultaneous and sequential bilinguals, both children and adults, performed equivalently, although the adult heritage speakers were more accurate on DOM than the children. Nevertheless, we agree with Meisel that, regardless of the outcome of the study, AoA is a very important variable that needs to be controlled in studies of heritage speakers.

Kupisch asks us to consider whether a simultaneous bilingual heritage speaker with two heritage language-speaking parents is more likely to have incomplete knowledge of the heritage language than a speaker with only one heritage languagespeaking parent. We do not fully understand this question; clearly, two parents would be able to provide more consistent input than only one parent. The findings from SánchezWalker (2013) mentioned earlier suggest that heritage speakers with only one heritage language-speaking parent tend to have a weaker command of the heritage language than those with two such parents. The children studied by Silva-Corvalán had only one Spanish-speaking parent, while the children studied by Anderson $(1999,2001)$ had two Spanish-speaking parents, yet all cases showed attrition and incomplete acquisition. These are only tendencies, however, and should not be interpreted as absolute hypotheses. As we have discussed at length, there are many variables that define bilinguals.

The issue of the baseline, or comparison group, for heritage speakers is also critical, as correctly pointed out by Meisel, Kupisch, Dąbrowska, Soltan and Musyken. Our position is that the nature of the baseline group has to be determined by the research question guiding the study. As we mentioned earlier, longitudinal studies provide an ideal format for teasing apart incomplete acquisition from attrition in childhood. In the absence 
of a longitudinal study, however, the same question can be approached, albeit indirectly, by conducting an experimental study and including different groups. For example, Polinsky (2011) compared child and adult heritage speakers of Russian in order to document potential attrition in the adult heritage speakers. Montrul et al. (submitted) included in their study a number of different groups: adult heritage speakers who differed on AoA (both simultaneous and sequential bilinguals), first-generation immigrants, young native speakers in the countries of origin matched in age, education, and region to the young adult heritage speakers, and a group of older native speakers matched for age, education and region to the first-generation immigrants. Including all these groups in the study allowed the authors to produce several meaningful juxtapositions. Potential language change in the immigrant community (or the original community) was assessed by comparing the grammars of first-generation immigrants to those of their counterparts in the countries of origin; a comparison of the first-generation immigrants and heritage speakers allowed the authors to assess whether changes observed in the heritage speakers have been transmitted or reinforced by the speech of the first generation. Finally, including heritage speakers who differed in AoA and intensity of exposure to the majority language allowed Montrul et al. to indirectly assess quantity of early input.

Most recently, Chung (2013) investigated accusative case ellipsis in Korean heritage speakers. Because accusative case ellipsis had not already been studied in Korean L1 acquisition, Chung first needed to identify the age at which monolingual children in Korea master this phenomenon; this piece of information was particularly important because the study sought to investigate issues of delayed development or incomplete acquisition in heritage speakers. Including the L1 acquisition group (in 
addition to a group of adult monolingual speakers from Korea) allowed Chung to observe the regular developmental schedule of accusative case ellipsis and then assess the extent to which U.S. heritage speakers of Korean had mastered this phenomenon. Especially when studying grammatical areas for which data on monolingual speakers does not exist, it is important to begin by collecting that data. In these cases, establishing the monolingual baseline is important for isolating the structure in question and validating the methodology.

On the other hand, we also agree with Kupisch that comparing bilinguals exposed to the same languages in different contexts can provide an ideal research design that allows us to look at heritage language phenomena from a different perspective. Kupisch cites her own study of German-French bilinguals as an example: since the study involved participants living in both France and Germany, the status of each language as minority or majority could be controlled for. The advantage of this design is that bilinguals are compared to bilinguals, rather than to monolinguals with very different language learning and education histories. Kupisch also mentions a study in progress of adult heritage speakers in Germany who show complete acquisition of the definiteness effect in Turkish. Conducting a comparison of these speakers with U.S. Turkish heritage speakers on the same phenomenon would be an ideal way for Kupisch and colleagues to determine whether the results obtained in their original study can be extended to other similar scenarios, or whether they are unique to Turkish speakers in Germany.

As mentioned earlier in this response paper and pointed out by Dąbrowska, our article - and in fact the field of heritage linguistics in general - is plagued by an absence of studies which compare schooled versus unschooled heritage speakers. The 
introduction of studies of this kind will be necessary to examine the degree to which written language and the written register impacts heritage language development. Many of the studies conducted to date in North America have included participants who are actually taking classes in their heritage language or a closely related variety at the time of the study; we refer to these participants as 'heritage language learners' in our article. We know of no studies that have separated heritage language learners from speakers who have never taken a class in their heritage language, but this needs to be done.

The take-home message here is that, when it comes to grouping heritage speakers and comparing groups of speakers, an important number of background variables need to be considered. To date, most of these variables have not received adequate attention in the literature.

Finally, Muysken raises the point that, in addition to the challenges of comparing different groups of speakers, it is also important that the tasks undertaken by these speakers in studies be comparable. The various studies we bring together in our keynote article do not make a distinction between tasks. Clearly, the proficiency of the speaker, the language variety, and the degree of literacy or schooling a speaker has received in the language all matter in determining choice of experimental task. Several studies have shown that heritage speakers' oral skills are better developed than their written skills in the heritage language, even when they are not entirely illiterate in the heritage language (Carreira and Kagan 2011). Heritage speakers of lower proficiency in the language need to be tested with oral-comprehension-based experiments (Polinsky 2011, Sherkina-Lieber et al. 2011), whereas fluent heritage speakers can be tested in both oral and written language. Grammaticality judgments have been useful in some studies but not in others 
(Montrul and Bowles 2009, Orfitelli and Polinsky, submitted). To deal with these issues, Montrul et al. (submitted) used multiple measures to investigate the same grammatical phenomenon: they tested oral and written production, elicited production, and auditory and written comprehension, and employed bimodal grammaticality judgment tasks with visual and auditory stimuli. If a heritage speaker's grammar deviates from the target grammar in terms of a particular grammatical property, this should be observed across different tasks. In general, it is safe to say that methodologies that emphasize the vernacular and implicit knowledge of the language, like those used with young children, will be the most appropriate for measuring the grammatical knowledge of heritage speakers, especially those who exhibit low proficiency in the language.

Fluent and highly literate heritage speakers can be studied with the methodologies used with educated monolinguals, but even so, we welcome the expansion of methodologies that allow us to understand heritage speakers' implicit knowledge of the language, as opposed to knowledge acquired through metalinguistic reflection in the classroom. Studies comparing heritage speakers and second language learners have documented important task effects: L2 learners do better in written tasks with ample time for metalinguistic reflection; heritage speakers do better in oral production tasks which do not require metalinguistic reflection (Bowles 2011, Montrul et al. 2008). We certainly agree with our colleagues that comparing heritage languages, heritage speakers and different contexts can be challenging if these methodological considerations are not taken into account.

Despite the many methodological challenges heritage speakers present for linguistic scientific research, we hope that linguists of all persuasions and experts from 
related disciplines can come together to embrace these challenges and to examine the nature of language and language acquisition in its various social and political contexts. Heritage language research has the potential to enrich the linguistic debate and help us answer the question of what we know when we know a language.

\section{References}

Albirini, Abdulkafi, and Elabbas Benmamoun. In press. Aspects of second language transfer in the oral production of Egyptian and Palestinian heritage speakers. International Journal of Bilingualism.

Albirini, Abdulkafi, and Elabbas Benmamoun. 2013. Factors affecting the retention of sentential negation in heritage Egyptian Arabic. Ms., Utah State University and University of Illinois.

Anderson, Raquel. 1999. Noun phrase gender agreement in language attrition. Preliminary results. Bilingual Research Journal 23, 318-337.

Anderson, Raquel. 2001. Lexical morphology and verb use in child first language loss. A preliminary case study investigation. International Journal of Bilingualism 5, $377-401$.

Aoun, Joseph, Elabbas Benmamoun, and Lina Choueiri. 2010. Arabic syntax. Cambridge: Cambridge University Press.

Baker, Mark. 2008. The syntax of agreement and concord. Cambridge: Cambridge University Press.

Baker, Mark. 2011. When agreement is for number and gender but not person. Natural Language and Linguistic Theory 29, 875-915. 
Beaudrie, Sara, and Marta Fairclough. 2012. Spanish as a heritage language in the United States. Washington, DC: Georgetown University Press.

Benmamoun, Elabbas. 2000. The feature structure of functional categories. New YorkOxford: Oxford University Press.

Benmamoun, Elabbas, Silvina Montrul, and Maria Polinsky. 2013. Heritage languages and their speakers: Opportunities and challenges for linguistics. This volume.

Bock, Kathryn, and Erica L. Middleton. 2011. Reaching agreement. Natural Language and Linguistic Theory 29, 1033-1069.

Borer, Hagit. 1996. The construct in review. In Jean Lowenstam, Jacqueline Lecarme and Ur Shlonsky (eds.) Studies in Afroasiatic grammar, 30-61. The Hague: Holland Academic Graphics.

Borik, Olga. 2006. Aspect and reference time. Oxford: Oxford University Press.

Bowles, Melissa. 2011. Measuring implicit and explicit linguistic knowledge: What can heritage language learners contribute? Studies in Second Language Acquisition $33,247-272$.

Bresnan, Joan. 2002. The lexicon in optimality theory. In Suzanne Stevenson and Paola Merlo (eds.) The lexical basis of syntactic processing: Formal, computational and experimental issues, 39-58. Amsterdam: John Benjamins.

Caldas, Stephen, and Suzanne Caron-Caldas. 2000. The influence of family, school and community on bilingual preference: Results from a Louisiana/Québec case study. Applied Psycholinguistics 21, 365-381. 
Carreira, María. 2004. Seeking explanatory adequacy: a dual approach to understanding the term "heritage language learner." Heritage Language Journal 2, 1. Available at: attp://www.heritagelanguages.org, accessed August 2013.

Carreira, María and Olga Kagan. 2011. The results of the national heritage language survey: implications for teaching, curriculum design, and professional development. Foreign Language Annals 44, 40-64.

Chambers, J.K., and Peter Trudgill. 1998. Dialectology. 2nd edition. Cambridge: Cambridge University Press.

Chomsky, Noam. 1965. Aspects of the theory of syntax. Cambridge, MA: MIT Press.

Chomsky, Noam. 1981. Lectures on government and binding, Dordrecht: Foris.

Chomsky, Noam. 1995. The minimalist program. Cambridge, MA: MIT Press.

Chomsky, Noam. 2001a. Beyond explanatory adequacy. (MIT occasional papers in linguistics. 20.) Cambridge, MA.

Chomsky, Noam. 2001b. Derivation by phase. In Michael Kenstowicz (ed.) Ken Hale: A life in language, 1-52, Cambridge, MA: MIT Press.

Chung, Eun-Sun (Eunice). 2013. Exploring the degree of native-likeness in bilingual acquisition. Second and heritage language acquisition of Korean case ellipsis. Ph.D. Dissertation, University of Illinois at Urbana-Champaign.

Cinque, Guglielmo, and Luigi Rizzi, 2010. The cartography of syntactic structures. In Berndt Heine and Heiko Narrog (eds.) The Oxford handbook of linguistic analysis, 51-66. New York: Oxford University Press. 
Davidson, Dan, and Maria Lekic. 2012. Comparing heritage and non-heritage learning outcomes and target language utilization in the overseas immersion context: A preliminary study of the Russian flagship. Russian Language Journal 62, 47-77.

De Bot, Kees, and Durk Gorter. 2005. A European perspective on heritage languages. The Modern Language Journal 89, 612-616.

De Houwer, Annick. 2009. Bilingual first language acquisition. Bristol: Multilingual Matters.

De Ruiter, Jacob. 1989. Young Moroccans in the Netherlands. An integrated approach to their language situation and acquisition of Dutch. Doctoral Dissertation, University of Utrecht.

Deuchar, Margaret, and Suzanne Quay. 2000. Bilingual acquisition: Theoretical implications of a case study. Oxford: Oxford University Press.

Dickey, Stephen. 2000. Parameters of Slavic aspect: A cognitive approach. Stanford: CSLI.

Döpke, Susanne. 1992. One parent, one language. An interactional approach. Amsterdam: John Benjamins.

Embick, David, and Rolf Noyer. 2001. Movement operations after syntax. Linguistic Inquiry 32, 555-595.

Extra, Guus, and Durk Gorter. 2001. The other languages of Europe. Clevedon: Multilingual Matters.

Extra, Guus, and Ludo Verhoeven. 1993. A bilingual perspective on Turkish and Moroccan children and adults in the Netherlands. In Guus Extra and Ludo 
Verhoeven (eds.) Immigrant languages in Europe, 67-100. Clevedon: Multilingual Matters.

Ezeizabarrena Segurola, María José. 2001. Dos tipos de morfología verbal, dos modos de adquisición en bilingües vasco-españoles. In Cecilia Rojas Nieto and Lourdes de León Pasquel (eds.) La adquisición de la lengua materna. Español, lenguas maya, euskera, 237-263. Mexico: Universidad Nacional Autónoma de México.

Filip, Hana. 2008. Events and maximalization. In Susan Rothstein (ed.) Theoretical and crosslinguistic approaches to the semantics of aspect, 217-256. Amsterdam: John Benjamins.

Filip, Hana. 2011. Aspectual class and Aktionsart. In Claudia Maienborn, Klaus von Heusinger, and Paul Portner (eds.) Semantics: An international handbook of natural language meaning, 1186-1217. Berlin: Mouton de Gruyter.

Filip, Hana. 2012. Lexical aspect. In Robert I. Binnick (ed.) The Oxford handbook of tense and aspect, 721-751. Oxford: Oxford University Press.

Fishman, Joshua. 1981. Language policy: Past, present, and future. In Charles Ferguson and Shirley Brice Heath (eds.) Language in the USA, 516-526. Cambridge: Cambridge University Press.

Fishman, Joshua. 2001. Can threatened languages be saved? Clevedon: Multilingual Matters.

Fishman, Joshua. 2006. Three-hundred plus years of heritage language education in the United States. In Guadalupe Valdés, Joshua Fishman, Rebecca Chávez and 
William Pérez (eds.) Developing minority language resources. The case of Spanish in California, 12-23. Clevedon: Multilingual Matters.

Flores, Cristina. 2010. The effect of age on language attrition: Evidence from bilingual returnees. Bilingualism: Language and Cognition 13, 533-546.

Franck, Julie, Glenda Lassi, Ulrich H. Frauenfelder, and Luigi Rizzi. 2006. Agreement and movement: A syntactic analysis of attraction. Cognition 101, 173-216.

Genesee, Fred. 1989. Early bilingual development. One language or two? Journal of Child Language 6, 161-179.

Genesee, Fred, Elena Nicoladis, and Johanne Paradis. 1995. Language differentiation in early bilingual development. Journal of Child Language 22, 611-631.

Haegeman, Liliane, and Terje Lohndal. 2010. Negative concord and multiple Agree: A case study of West Flemish. Linguistic Inquiry 41, 181-211.

Halle, Morris, and Alec Marantz. 1993. Distributed Morphology and the pieces of inflection. In Kenneth Hale and Samuel Jay Keyser (eds.) The view from Building 20: Essays in linguistics in honor of Sylvain Bromberger, 111-176. Cambridge, MA: MIT Press.

He, Agnes Weiyun. 2010. The heart of heritage: Sociocultural dimensions of heritage language learning. Annual Review of Applied Linguistics 30, 66-82.

Hindley, Reg. 1990. The death of the Irish language. New York: Routledge.

Hornberger, Nancy, and Shuhan Wang. 2008. Who are our heritage language learners? Identity and biliteracy in heritage language education in the United States. In Donna Brinton, Olga Kagan and Susan Bauckus (eds.) Heritage language education: A new field emerging, 3-38. New York: Routledge. 
Jackendoff, Ray. 1997. The architecture of the language faculty. Cambridge, MA: MIT Press.

Kayne, Richard S. 2010. Comparisons and contrasts. Oxford-New York: Oxford University Press.

Kayne, Richard S. 2013. Comparative syntax. Lingua 130, 132-151.

King, Kendall, and Joanna Ennser-Kananen. 2013. Heritage languages and language policy. In Carol Chapelle (ed.) The encyclopedia of applied linguistics, 1-4. Malden, NJ: Blackwell.

Kortmann, Bernd. 2002. New prospects for the study of English dialect syntax. In Sjef Barbiers, Leonie Cornips and Susanne van der Kleij (eds.) Syntactic microvariation, 185-213. Electronic publication, ttp://www.meertens.knaw.nl/project-ten/sand/synmic (accessed August 18, 2013).

Laleko, Oksana. 2010. The syntax-pragmatics interface in language loss: Covert restructuring of aspect in Heritage Russian. Ph.D. Dissertation, University of Minnesota.

Laleko, Oksana, and Maria Polinsky. In press. Marking topic or marking case? Heritage Language Journal.

Lanza, Elizabeth. 2004. Language mixing in infant bilingualism: A sociolinguistic perspective. New York: Oxford University Press.

Lightfoot, David. 1991. How to set parameters. Arguments from language change. Cambridge, MA: MIT Press.

Meisel, Jürgen (ed.) 1994. Bilingual first language acquisition. French and German grammatical development. Amsterdam: John Benjamins. 
Meisel, Jürgen. 2001. The simultaneous acquisition of two first languages. In Jasone Cenoz and Fred Genesee (eds.) Trends in bilingual acquisition, 11-41. Amsterdam: John Benjamins.

Meisel, Jürgen. 2007. The weaker language in early child bilingualism: Acquiring a first language like a second language? Applied Psycholinguistics 28, 495-514.

Merino, Barbara. 1983. Language loss in bilingual Chicano children. Journal of Applied Developmental Psychology 4, 277-294.

Montrul, Silvina. 2002. Incomplete acquisition and attrition of Spanish tense/aspect distinctions in adult bilinguals. Bilingualism: Language and Cognition 5, 39-68.

Montrul, Silvina. 2008. Incomplete acquisition in bilingualism: Re-examining the age factor. Amsterdam: John Benjamins.

Montrul, Silvina, and Melissa Bowles. 2009. Back to basics: Differential Object Marking under incomplete acquisition in Spanish heritage speakers. Bilingualism: Language and Cognition. 12, 363-383.

Montrul, Silvina, and Noelia Sánchez-Walker. 2013. Differential object marking in child and adult Spanish heritage speakers. Language Acquisition 20, 1-24.

Montrul, Silvina, Rakesh Bhatt, and Roxana Girju. Submitted. Differential Object Marking in Spanish, Hindi and Romanian as heritage languages.

Montrul, Silvina, Rebecca Foote, and Silvia Perpiñán. 2008. Gender agreement in adult second language learners and Spanish heritage speakers: The effects of age and context of acquisition. Language Learning 58, 3-53. 
Müller, Natascha, and Aafke Hulk. 2001. Crosslinguistic influence in bilingual language acquisition: Italian and French as recipient languages. Bilingualism: Language and Cognition 4, 1-21.

Myers-Scotton, Carol. 2002. Contact linguistics: Bilingual encounters and grammatical outcomes. Oxford: Oxford University Press.

Orfitelli, Robyn, and Maria Polinsky. Submitted. When performance masquerades as competence.

Otheguy, Ricardo, and Ana Celia Zentella. 2012. Spanish in New York. Oxford: Oxford University Press.

Pavlinic, Andrina. 1993. Croatian or Serbian as a diaspora language in Western Europe. 1993. In Guus Extra and Ludo Verhoeven (eds.) Immigrant languages in Europe, 101-118. Clevedon: Multilingual Matters.

Perlmutter, David M. 1998. Interfaces: explanation of allomorphy and the architecture of grammars. In Stephen G. Lapointe, Diane K. Brentari, and Patrick M. Farrell (eds.) Morphology and its relation to phonology and syntax, 307-338. Stanford, CA: CSLI.

Pfaff, Carol. 1991. Turkish in contact with German. Language maintenance and loss among immigrant children in West Berlin. International Journal of the Sociology of Language 90, 77-129.

Pfaff, Carol. 1993. Turkish language development in Germany. A bilingual perspective on Turkish and Moroccan children and adults in the Netherlands. In Guus Extra and Ludo Verhoeven (eds.) Immigrant languages in Europe, 119-146. Clevedon: Multilingual Matters. 
Pfaff, Carol. 1994. Early bilingual development of Turkish children in Berlin. In Guus Extra and Ludo Verhoeven (eds.) The crosslinguistic study of bilingual development, 76-97. Amsterdam: North Holland.

Polinsky, Maria. 2011. Reanalysis in adult heritage language: A case for attrition. Studies in Second Language Acquisition 33, 305-328.

Polinsky, Maria, and Olga Kagan. 2007. Heritage languages: in the "wild" and in the classroom. Language and Linguistics Compass 1, 368-395.

Pollock, Jean-Yves. 1989. Verb movement, UG and the structure of IP. Linguistic Inquiry $20,365-424$.

Preminger, Omer. 2011a. Agreement as a fallible operation. Ph.D. Dissertation, MIT.

Preminger, Omer. 2011b. Asymmetries between person and number in syntax: A commentary on Baker's SCOPA. Natural Language and Linguistic Theory 29, 917-937.

Reetz-Kurashige, Anita. 1999. Japanese returnees' retention of English-speaking skills: Changes in verb usage over time. In Lynne Hansen (ed.) Second language attrition in Japanese contexts, 21-58. New York: Oxford University Press.

Ritter, Elizabeth. 1988. A head-movement approach to construct state noun phrases. Linguistics 26, 909-929.

Sánchez-Walker, Noelia. 2013. Comprehension of subject and object relative clauses in Spanish heritage speakers and L2 learners of Spanish. Qualifying doctoral paper. University of Illinois at Urbana-Champaign. 
Schaufeli, Anneli. 1993. Turkish language development in the Netherlands. In Guus Extra and Ludo Verhoeven (eds.) Immigrant languages in Europe, 120-147. Clevedon: Multilingual Matters.

Schmid, Monika. First language attrition. 2011. Cambridge: Cambridge University Press. Schmidt, Annette. 1985. Young people's Dyirbal. Cambridge: Cambridge University Press.

Serratrice, Ludovica. 2001. The emergence of verbal morphology and the lead-lag pattern issue in bilingual acquisition. In Jasone Cenoz and Fred Genesee (eds.) Trends in bilingual acquisition, 43-70. Amsterdam: John Benjamins.

Serratrice, Ludovica. 2002. Overt subjects in English: Evidence for the marking of person in an English-Italian bilingual child. Journal of Child Language 29, 327-355.

Sherkina-Lieber, Marina. 2011. Comprehension of Labrador Inuttitut functional morphology by receptive bilinguals. Ph.D. Dissertation, University of Toronto.

Sherkina-Lieber, Marina, Ana Teresa Pérez-Leroux, and Alana Jones. 2011. Grammar without speech production. The case of Inuttitut heritage receptive bilinguals. Bilingualism: Language and Cognition 14, 301-317.

Silva-Corvalán, Carmen. 1994. Language contact and change: Spanish in Los Angeles. Oxford: Oxford University Press.

Silva-Corvalán, Carmen. 2014. Bilingual Language Acquisition: Spanish and English in the first six years. Cambridge, UK: Cambridge University Press.

Tomiyama, Machiko. 1999. The first stage of second language attrition: A case study of a Japanese returnee. In Lynne Hansen (ed.) Second language attrition in Japanese 
contexts, 59-79. New York: Oxford University Press.

Tomiyama, Machiko. 2008. Age and proficiency in L2 attrition: Data from two siblings. Applied Linguistics 30, 253-275.

Valdés, Guadalupe. 2000. Introduction. Spanish for Native Speakers, Volume I. AATSP Professional Development Series Handbook for teachers K-16. New York, NY: Harcourt College.

Valdés, Guadalupe. 2005. Bilingualism, heritage learners, and SLA research: Opportunities lost or seized? Modern Language Journal 89, 410-426.

Van Deusen-Scholl, Nelleke. 2003. Toward a definition of heritage language: sociopolitical and pedagogical considerations. Journal of Language, Identity and Education 2, 211-230.

Verhoeven, Ludo. 1991a. Acquisition of Turkish in a monolingual and bilingual setting. In Hendrik Boeschoten and Ludo Verhoeven (eds.) Turkish linguistics today, 113149. Leiden: Brill.

Verhoeven, Ludo. 1991b. Predicting minority children's bilingual proficiency: child, family and Institutional factors. Language Learning 41, 241-256.

Verhoeven, Ludo and Hendrik Boeschoten. 1986. First language acquisition in a second language environment. Journal of Applied Psycholinguistics 7. 241-256.

Verkuyl, Henk. 1999. Aspectual issues: Studies on time and quantity. Stanford: CSLI.

Verkuyl, Henk. 2012. Compositionality. In In Robert I. Binnick (ed.) The Oxford handbook of tense and aspect, 563-585. Oxford: Oxford University Press.

Viswanath, Arun. 2013. Heritage English in Israeli Children. Honors Thesis, Harvard University. 
Von Raffler-Engel, Walburga. 1965. Del bilinguismo infantile. Archivio Glottologico Italiano 50. 175-180.

Yang, Charles. 2002. Knowledge and learning in natural language. Oxford: Oxford University Press.

Yip, Virginia, and Stephen Matthews. 2007. The bilingual child: Early development and language contact. Cambridge: Cambridge University Press.

Yoshitomi, Asako. 1999. On the loss of English as a second language by Japanese returnee children. In Lynne Hansen (ed.) Second language attrition in Japanese contexts, 80-111. New York: Oxford University Press.

Zeijlstra, Hedde. 2008. Negative concord is syntactic agreement. Ms., University of Amsterdam. 